\title{
Hubungan Lama Bermain Game dengan Jumlah Jam Tidur pada Siswa SD Negeri Pannyikkokang 1 Kota Makassar
}

\author{
Mikawati $^{1 *}$, Lenni Rukmini ${ }^{2}$ \\ 1*. STIKES Panakkukang Makassar, Jl. Adiyaksa No.2, Kota Makassar, Indonesia, 90222 \\ 2. STIKES Panakkukang Makassar, Jl. Adiyaksa No.2, Kota Makassar, Indonesia, 90222 \\ *e-mail:mikawati.skp@gmail.com
}

\begin{abstract}
Game is one of the developments of computerized technology that is very interesting and much more popular not only used by adolescents and adults, but also used by the children's a specialty in elementary school. The negative impact of Playing games have been found such as decrease the number of hours of sleep. The purpose of this study was to investigate the relationship between time spend playing games with number of sleep in students of SD Pannyikkokang 1 in Makassar. A cross sectional study based on a self-reported participants using a random sampling technique. SPSS software was applied in statistical analysis using Chi-square test with a significance level of p value $<0.05$. The result of our study based on analysis statistic was p 0.003, this means have a relationship between time spend playing games with hours of sleep. The conclusion of our study was even though playing games has a positive impact on children to develop intelligence but to avoid negative impacts given gadgets and computers that can affect children's health.
\end{abstract}

Keyword : Hours of sleep, Time spend playing games

\begin{abstract}
Abstrak
Game adalah salah satu dari perkembangan teknologi komputerisasi yang sangat menarik dan banyak digemari tidak hanya digunakan oleh kalangan remaja dan dewasa, tetapi juga digunakan oleh kalangan usia anak sekolah. Bermain game dapat memberikan dampak negatif salah satunya adalah jumlah jam tidur yang yang kurang dari kebutuhan. Tujuan Penelitian ini adalah untuk mengetahui hubungan lama bermain game dengan jumlah jam tidur pada siswa SD Negeri Pannyikkokang 1 Kota Makassar. Penelitian ini merupakan jenis penelitian deskriptif analitik dengan pendekatan cross sectional. Pangambilan sampel pada penelitian ini dilakukan dengan tehnik random sampling dan jumlah sampel sebanyak 90 responden. Instrumen yang digunakan adalah kuesioner, pengolahan data dengan menggunakan program SPSS dengan uji statistik Chi-Square dan tingkat kemaknaan $p$ value $<0,05$. Berdasarkan hasil analisis hubungan lama bermain game dengan jumlah jam tidur diperoleh nilai $p=0,003$ berarti ada hubungan bermakna antara lama bermain game dengan jumlah jam tidur. Diharapkan penjelasan ke orangtua tentang dampak yang ditimbulkan akibat bermain game, walaupun bermain game mempunyai dampak positif bagi anak untuk mengembangkan kecerdasannya tapi untuk menghindari dampak negatif sebaiknya anak usia sekolah tidak diberi gadget dan komputer yang dapat berpengaruh pada kesehatan anak.
\end{abstract}

Kata kunci : Lama bermain game, jumlah jam tidur 


\section{Pendahuluan}

Game adalah salah satu dari perkembangan teknologi komputerisasi yang sangat menarik dan banyak digemari tidak hanya digunakan oleh kalangan remaja dan dewasa, tetapi juga digunakan oleh kalangan usia anak sekolah (Widea,2015). Di Jepang, pemerintah telah mengakui masalah tersebut menjadi sebuah studi oleh Departemen Pendidikan, yang telah menyebabkan pengembangan "fasting camp" di mana individu yang menderita dampak negatif dari internet dan kecanduan game online dibantu dengan memutuskan teknologi secara keseluruhan. Telah dinyatakan bahwa semakin tinggi penetrasi internet dan penerimaan game online, semakin tinggi prevalensi masalah. Sebagian menjelaskan tingkat prevalensi lebih tinggi dilaporkan di negara-negara Asia Tenggara (Kuss, 2011).

Di dunia pada tahun 2013, jumlah gamer sebanyak 1,3 milyar. Saat ini jumlah populasi dunia sebanyak 7,1 milyar artinya $17 \%$ total penduduk adalah gamer (Liputan 6.com).

Di Indonesia sendiri data tentang penggunaan internet dirilis oleh Asosiasi Penyelenggara Jasa Internet Indonesia (APJII) pada tahun 2012 bahwa sebanyak 18,5\% internet digunakan untuk game online. Indonesia mempunyai jumlah pemain games yang cukup besar. Namun sayangnya karena keterbatasan data hasil penelitian mengenai hal ini jumlah pemain games di Makassar belum diketahui secara tepat.

Pada saat melakukan observasi awal di sekolah SD Negeri Pannyikkokang 1 Kecamatan Panakkukang Kota Makassar, siswa SD Negeri Pannyikkokang 1 membawa Android, dimana saya melihat selain, android tersebut digunakan untuk menghubungi orang tua untuk menjemput sepulang sekolah, juga digunakan untuk bermain game.

Berdasarkan uraian diatas, maka peneliti merasa perlu melakukan penelitian tentang hubungan lama bermain game dengan jumlah jam tidur siswa SD Negeri Pannyikkokang 1 Kota Makassar.

\section{Metode}

Penelitian ini dilaksanakan pada tanggal 12 Maret s/d 12 April 2018 di SD Negeri Pannyikkokang 1 Kecamatan Panakkukang Kota Makassar. Populasi pada penelitian ini adalah seluruh anak SD Negeri Pannyikkokang 1, kelas 4 yang berjumlah 35 siswa, kelas 5 yang berjumlah 37 siswa, dan kelas 6 yang berjumlah 45 siswa di SD Negeri Panyyikkokang 1, jumlah keseluruhan 117 siswa dengan jumlah sampel adalah 90 orang.

1. Kriteria inklusi

a. Anak SD Negeri Pannyikkokang I kelas 4, 5 dan 6

b. Memiliki pengetahuan membaca dan menulis

c. Anak yang bermain game

d. Anak-anak yang bersedia menjadi responden

2. Kriteria eksklusi

Anak yang tidak pernah hadir di sekolah dan tidak pernah hadir selama penelitian.

Pengumpulan dan Pengolahan Data

Data hasil penelitian diperoleh dengan mengumpulkan data primer dan data sekunder. Data primer adalah data yang diperoleh langsung dari responden melalui pengisian kuesioner dan alat yang digunakan adalah alat tulis menulis serta bahan yang digunakan adalah kuesioner. Sedangkan data sekunder adalah data yang di dapatkan dari hasil observasi siswa

Dalam penelitian ini digunakan kuesioner yang disebarkan kepada responden yang menjadi sampel pilihan. Adapun urutan prosedur penelitian sebagai berikut : Sebelum kuesioner diserahkan kepada responden, peneliti memberikan penjelasan tentang tujuan penelitian, Setelah responden memahami tujuan penelitian, maka responden diminta kesediaannya untuk mengisi kuesioner, Jika responden telah menyatakan bersedia, maka kusioner diberikan dan responden diminta untuk mempelajari terlebih dahulu tentang cara pengisian kuesioner, setelah kuesioner selesai diisi oleh responden, selanjutnya dikumpulkan dan dipersiapkan untuk diolah dan dianalisis.

\section{Analisa Data}

Setelah data tersebut dilakukan editing, koding, dan tabulasi maka selanjutnya dilakukan Analisis data berupa : Analisis univariat yaitu data yang diperoleh dari masing-masing variabel dimasukkan kedalam variabel frekuensi. Selanjutnya dilakukan Analisis bivariat yaitu untuk mengetahui atau menguji hubungan antara variabel independen dengan variabel dependen, yang dilakukan dengan uji Chi-Square pada program SPSS 16,0 dengan nilai kemaknaan $\alpha=$ 0,05 . 


\section{Hasil}

Tabel 1. Distribusi frekuensi responden berdasarkan jenis kelamin di SD Negeri pannyikkokang 1 kota makassar

\begin{tabular}{ccc}
\hline Jenis Kelamin & Frekuensi & Persentase (\%) \\
\hline Laki-laki & 51 & 56,7 \\
Perempuan & 39 & 43,3 \\
\hline Jumlah & 90 & 100,0 \\
\hline
\end{tabular}

Pada tabel 1 menunjukkan data karakteristik responden bahwa kelompok jenis kelamin responden laki-laki sebanyak 51 orang denga $56,7 \&$ dan perempuan sebanyak 39 orang dengan $43,3 \%$.

Tabel 2. Distribusi frekuensi responden berdasarkan umur di SD Negeri pannyikkokang 1 kota makassar

\begin{tabular}{ccc}
\hline Umur & Frekuensi & Persentase (\%) \\
\hline Umur 8-9 Tahun & 7 & 7,8 \\
Umur 10-11 Tahun & 47 & 52,2 \\
Umur 12-13 Tahun & 36 & 40,0 \\
\hline Jumlah & 90 & 100,0 \\
\hline
\end{tabular}

Pada tabel 2 menunjukkan data karakteristik responden bahwa berdasarkan kelompok umur 8-9 tahun sebanyak 7 orang dengan 7,8\%, 10-11 tahun sebanyak 47 orang dengan 52,2\%, dan umur 12-13 tahun sebanyak 36 orang dengan 40,0\%.

Tabel 3. Distribusi frekuensi responden berdasarkan kelas di SD Negeri pannyikkokang 1 kota makassar

\begin{tabular}{ccc}
\hline Kelas & Frekuensi & Persentase (\%) \\
\hline Kelas 6 & 46 & 51,1 \\
Kelas 5 & 23 & 25,6 \\
Kelas 4 & 21 & 23,3 \\
\hline Jumlah & 90 & 100,0 \\
\hline
\end{tabular}

Pada tabel 3 menunjukkan data karakteristik responden bahwa berdasarkan kelompok kelas tertinggi yaitu kelas 6 dengan jumlah 46 orang dengan $51,1 \%$, kelas 5 sebanyak 23 orang dengan $25,6 \%$ dan kelas 4 sebanyak 21 orang dengan $23,3 \%$.

Tabel 4. Distribusi responden berdasarkan lama bermain game di SD Negeri pannyikkokang 1 kota makassar

\begin{tabular}{ccc}
\hline Lama bermain & Frekuensi & Persentase (\%) \\
\hline Lama & 55 & 61,1 \\
Singkat & 35 & 38,9 \\
\hline Jumlah & 90 & 100,0 \\
\hline
\end{tabular}

Pada tabel 4 diatas menunjukkan data 90 responden, berdasarkan lama bermain game yang dimiliki oleh responden yang paling tinggi yaitu bermain game dalam waktu yang lama sebanyak 55 responden $(61,1 \%)$, dan yang paling sedikit yaitu bermain game dalam waktu yang singkat sebanyak 35 responden (38,9\%). 
Tabel 5. Distribusi responden berdasarkan jumlah jam tidur pada siswa SD Negeri pannyikkokang 1 kota makassar.

\begin{tabular}{ccc}
\hline Jumlah Jam Tidur & Frekuensi & Persentase (\%) \\
\hline Tidak Terpenuhi & 66 & 73,3 \\
Terpenuhi & 24 & 26,7 \\
\hline Jumlah & 90 & 100,0 \\
\hline
\end{tabular}

Pada tabel 5 diatas menunjukkan data 90 responden, berdasarkan jumlah jam tidur responden yang paling tinggi yaitu jumlah jam tidur tidak terpenuhi yaitu sebanyak 66 responden $(73,3 \%)$, dan yang paling rendah yaitu jumlah jam tidur terpenuhi yaitu sebanyak 24 responden $(26,7 \%)$.

Tabel 6. Hubungan lama bermain game dengan jumlah jam tidur siswa SD Negeri pannyikkokang 1 kota makassar.

\begin{tabular}{|c|c|c|c|c|c|c|c|}
\hline \multirow{3}{*}{$\begin{array}{c}\text { Lama } \\
\text { Bermain } \\
\text { Game }\end{array}$} & \multicolumn{4}{|c|}{ Jumlah Jam Tidur } & \multirow{2}{*}{\multicolumn{2}{|c|}{ Jumlah }} & \multirow{3}{*}{$\mathbf{p}$} \\
\hline & \multicolumn{2}{|c|}{ Tidak Terpenuhi } & \multicolumn{2}{|c|}{ Terpenuhi } & & & \\
\hline & $\mathbf{n}$ & $\%$ & $\mathbf{n}$ & $\%$ & $\mathbf{n}$ & $\%$ & \\
\hline Lama & 47 & 52,2 & 8 & 8,9 & 55 & 61,1 & \multirow{3}{*}{$\begin{array}{l}0,0 \\
03\end{array}$} \\
\hline Singkat & 19 & 21,1 & 16 & 17,8 & 35 & 38,9 & \\
\hline Jumlah & 66 & 73,3 & 24 & 26,7 & 90 & 100,0 & \\
\hline
\end{tabular}

Pada tabel 4 diatas didapatkan data yang mempengaruhi jumlah jam tidur anak yang dilihat dari 90 responden adalah yang lama bermain game sebanyak 55 responden dengan jumlah jam tidur paling banyak yaitu tidak terpenuhi sebanyak 47 responden $(52,2 \%)$ dan yang terpenuhi sebanyak 8 responden $(8,9 \%)$.

Sedangkan dari 35 responden yang memiliki waktu singkat dalam bermain game dengan jumlah jam tidur yang paling banyak yaitu tidak terpenuhi sebanyak 19 responden $(21,1 \%)$ dan yang terpenuhi sebanyak 16 responden $(17,8 \%)$.

Berdasarkan hasil analisis statistik menggunakan uji Chi-square, diperoleh nilai $\mathrm{p}=0.003<0.05$, yang berarti terdapat hubungan antara lama bermain game dengan jumlah jam tidur siswa SD Negeri Pannyikkokang 1 Kota Makassar tahun 2018.

\section{Pembahasan}

1. Lama bermain game

Dari tabel 4 menunjukkan data 90 responden, berdasarkan lama bermain game yang dimiliki oleh responden rata-rata responden yang bermain bermain game dalam waktu yang lama yaitu sebanyak 55 responden $(61,1 \%)$. Sedangkan responden yang bermain game dalam waktu yang singkat sebanyak 35 responden (38,9\%).

Menurut peneliti dari hasil kusioner, wawancara dan observasi didapatkan bahwa siswa yang bermain game dalam kurung waktu lama banyak karena dalam bermain game ada waktu-waktu tertentu dalam menyelesaikan permainan. Contohnya seperti permainan ludo dan mobile legends membutuhkan waktu yang cukup lama dalam menyelesaikan 1x permainan sedangkan dalam bermain game kalah selalu menimbulkan rasa ingin mencoba kembali untuk memenangkan permainan. Sedangkan responden yang bermain game dalam kurung waktu singkat lebih sedikit karena adanya aktivitas lain yang dapat dilakukan seperti mengaji, sekolah, menonton TV, olahraga dan liburan bersama keluarga.

2. Jumlah jam tidur

Dari tabel 5.3 menunjukkan data 90 responden, berdasarkan jumlah jam tidur yang dimiliki oleh responden rata-rata responden jumlah jam tidur tidak terpenuhi yaitu sebanyak 66 responden $(73,3 \%)$, sedangkan responden yang jumlah jam tidurnya terpenuhi yaitu sebanyak 24 responden $(26,7 \%)$.

Menurut peneliti dari hasil kusioner, wawancara dan observasi bahwa ada beberapa responden mengeluh adanya perubahan jumlah jam tidur tetapi ada juga yang jumlah jam tidurnya tetap terpenuhi. Hal ini disebabkan karena jumlah jam tidur tidak hanya dipengaruhi oleh lama bermain game tetapi juga dapat dipengaruhi karena adanya gangguan tidur seperti insomnia, hipersomnia, parasomnia, mendengkur dan mengigau selain dari itu juga ada faktor lain seperti penyakit, latihan/kelelahan, stres psikologi, obat, nutrisi, lingkungan dan motivasi.

3. Hubungan lama bermain game dengan jumlah jam tidur anak di SD Negeri pannyikokkang 1

Berdasarkan hasil penelitian yang telah dilakukan terhadap 90 responden anak yang berada di SD Negeri Pannyikokkang 1 hasil analisa univariat menunjukan bahwa frekuensi dan presentase responden yang bermain game adalah yang mengalami lama bermain game sebanyak 55 responden $(61,1 \%)$ anak dan yang memiliki jumlah jam tidur terpenuhi sebanyak 8 responden $(8,9 \%)$ anak sedangkan anak yang memiliki jumlah jam tidur tidak 
terpenuhi sebanyak 47 reponden $(52,2 \%)$ dan responden yang bermain game singkat sebanyak 35 responden $(38,9 \%)$ anak yang memiliki jumlah jam tidur tidak terpenuhi sebanyak 19 responden $(21,1 \%)$ anak dan yang memiliki jumlah jam tidur terpenuhi sebanyak 16 reponden $(17,8 \%)$ anak. Dari hasil bivariat menunjukan bahwa ada hubungan lama bermain game dengan jumlah jam tidur siswa di SD Negeri Panyyikkokang 1 yang di buktikan uji chi-square, nilai $\mathrm{p}=0,003<(\mathrm{p} \alpha=0,05)$.

Walaupun hasil penelitian ini menunjukkan bahwa ada hubungan antara lama bermain game dengan jumlah jam tidur, dalam penelitian ini di dapatkan data bahwa terdapat responden yang bermain game dalam kategori lama namun jumlah jam tidurnya terpenuhi, hal ini disebabkan karena level aktivitas selain bermain game sedikit sehingga jumlah jam tidurnya dapat terpenuhi didukung teori chess mcdoogle (2010) tentang mekanisme tidur tidur memiliki 4 variabel utama yang mempengaruhi tidur: circadian Rhythm atau ritme suhu tubuh, melatonin dan cahaya matahari, level aktivitas, keterjagaan sebelumnya.

Dalam penelitian ini juga didapatkan responden yang bermain game dalam kategori singkat namun jumlah jam tidurnya tidak terpenuhi, hal ini disebabkan karena selain bermain game, level aktivitas yang tinggi adanya faktorfaktor lain seperti penyakit dan gangguan tidur yang dapat menyebabkan jumlah jam tidurnya tidak terpenuhi, hal ini didukung teori yang menjelaskan bahwa Faktor-faktor yang mempengaruhi tidur antara lain: penyakit, latihan dan kelelahan, stres psikologis, obat, nutrisi, lingkungan dan motivasi Menurut Alimul (2006). Selain dari faktorfaktor yang mempengaruhi tidur, juga ada jenis-jenis gangguan tidur yang sering terjadi menurut Tarwoto \& Waronah (2006) adalah: insomnia, hipersomnia, parasomnia, narcolepsey, apnoe tidur dan mendengkur dan mengigau.

Hal tersebut didukung oleh penelitian Dworak et al (2007) dalam penelitian yang berjudul Impact of Singular Excessive Computer Game and Television Exposure on Sleep Patterns and Memory Performance of School-aged Children menunjukkan permainan game berpengaruh terhadap pengurangan jumlah SWS (Slow Wave Sleep) atau biasa juga disebut dengan tidur Non REM dan memperpanjaang SOL (Sleep Onset Latency). Sleep onset latency adalah periode antara waktu subjek naik tempat tidur untuk tidur tanpa melakukan aktivitas lain dengan waktu subjek mulai tidur sebenarnya yang dinilai oleh actiware software. Peningkatan sleep onset latency (SOL) akibat bermain game menyebabkan kesulitan anak dalam jatuh tidur, sering terbangun di malam hari dan penurunan jumlah tidur itu sendiri.

Wong and Hockenberry (2005) mengemukakan bahwa pada saat seseorang bermain game maka korteks cerebral mengeluarkan norepinephrine dan otak tengah mengeluarkan neurotransmitter dopamine. Kedua neurotransmitter tersebut keduanya merupakan bagian dari sistem aktivasi retikular (SAR) yang berfungsi dalam mempertahankan keadaan terjaga. Gelombang elektromagnetik dan juga cahaya yang dihasilkan menyebabkan terhambatnya produksi hormon melatonin yang di keluarkan oleh kelenjar hypotalamus yang fungsinya penurunan keterjagaan (Thomas et al, 2005), sehingga bila melatonin terus diproduksi maka seseorang tidak bisa segera melakukan aktivitas tidur.

Dampak negatif dari bermain game meliputi dampak secara sosial, psikis dan fisik dari kecanduan main game sedangkan menurut tridhonanto (2011) dalam buku optimalkan potensi anak dengan game menjelaskan tentang pengaruh positif game (dikutip jenab dan Hudaya, A. 2015) adalah sebagai berikut membuat orang pintar, meningkatkan ketajaman mata, rajin membaca, memulihkan kondisi tubuh, dan meningkatkan kecepatan dalam mengetik

Anak usia sekolah membutuhkan waktu untuk tidur, tetapi sering berkurang karena berbagai tuntutan seperti pekerjaan rumah, olah raga, dan aktivitas lainnya. Mereka banyak menghabiskan waktu untuk menonton televisi. Kegiatan ini dapat menyebabkan kesulitan tidur dan sedikitnya waktu tidur untuk mereka sejalan dengan penelitian oleh Berman (2008) yang mengatakan bahwa beberapa anak masih melakukan tidur siang bila tidak ada kegiatan tambahan pada waktu siang hari, akan tetapi sekarang waktu kosong yang mereka punya pada siang hari lebih mereka luangkan waktu untuk bermain game. Para ilmuwan Universitas Harvard dalam melakukan penelitian menunjukkan bahwa fokus otak seseorang ada pada tahap minimum ketika ia baru saja bangun tidur. Dibutuhkan waktu antara 15-30 menit untuk dapat mengembalikan kemampuan pikiran. Oleh karena itu disarankan agar seseorang segera setelah bangun tidur melakukan beberapa latihan ringan untuk memulihkan aktivitas otak. Tridhonanto dan Beranda, (2011) mengatakan bahwa perubahan jumlah jam tidur yang berdampak negatif pada anak disebabkan karena permainan game yang tidak terkontrol sehingga mempengaruhi jam biologis seseorang, hal ini sejalan dengan penelitian dari Sanditaria (2011) yang mengatakan bahwa beberapa dampak negatif yang disebabkan memainkan game yaitu anak menjadi sulit atau lupa untuk makan, tidak merawat diri dan mempunyai waktu tidur yang kurang.

Hasil penelitian ini dapat disimpulkan bahwa di SD Negeri Pannyikkokang 1 lebih banyak yang bermain game dan sangat berdampak pada jumlah jam tidur siswa. Hasil penelitian ini menunjukkan bahwa terdapat hubungan lama bermain game dengan jumlah jam tidur anak, dapat dilihat bahwa jumlah jam tidur anak yang bermain game lama kebanyakan anak memiliki jumlah jam tidur yang tidak terpenuhi dari 90 responden terdapat 55 responden $(61,1 \%)$ yang bermain game lama 47 responen $(52,2 \%)$ yang tidak terpenuhi jumlah jam tidurnya dan 8 responden $(8,9 \%)$ yang terpenuhi jumlah jam tidurnya, dibangdingkan dengan yang bermain game singkat dari 35 responden 
$(38,9 \%)$ terdapat 19 responden $(21,1 \%)$ yang jumlah jam tidurnya tidak terpenuhi dan 16 responden $(17,8 \%)$ yang terpenuhi jumlah jam tidurnya. Jadi hal ini tergantung dari berapa lama anak bermain game, semakin lama anak bermain game maka akan mempengaruhi jumlah jam tidurnya dan semakin singkat anak bermain game maka akan terpenuhi jumlah jam tidurnya.

\section{Kesimpulan}

Ada hubungan lama bermain game dengan jumlah jam tidur siswa SD Negeri Pannyikkokang 1 Kota Makassar

\section{Referensi}

Ernawati Widea. (2015). Pengaruh Penggunaan Gadget Terhadap Penurunan Tajam Penglihatan Pada Anak Usia Sekolah (6-12 Tahun) Di SD Muhammadiyah 2 Pontianak Selatan. Pontianak. Universitas Tanjungpura. Jurnal Proners, Vol. 3, No. 1, Tahun 2015

Hidayat, A.A (2012) Pengantar Kebutuhan Dasar Manusia. Jakarta: Salemba Medika

Jaenab, Hudaya , Adeng. (2015) Pengaruh adiktif Game online Terhdap Prestasi Belajar Siswa Kelas X SMAN 1 Cileungsi, Jurnal Pendidikan. Vol. 2 No, 12015.

Kuss, D.J. \& Griffiths, M.D. (2011b). —Excessive online social networking: Can adolescents become addicted to Facebook. Education and Health.29. (4), 68-71.

Kozier (2004) Fundamental Of Nursing :Concepts, Process, and Practice, 7th Ed.USA : Person Prentice Hall

Potter \& Perry (2006) Buku Ajar Fundamental Keperawatan: Konsep, Proses Dan Praktik. Vol, 2. Edisi 4. Jakarta : EGC

Sanditaria, W, Fitri,S,Y,R, Mardhiyah, A. (2011). Adiksi Bermain Game Online pada Anak Usia Sekolah di Warung Internet Penyedia Game Online Jatinangor Sumedang. Jurnal Fakultas Ilmu Keperawatan Universitas Padjajaran. Bandung.

Tarwoto dan Wartonah.,2015. Kebutuhan Dasar Manusia dan Proses Keperawatan . Edisi :4 .Jakarta

Tridhonanto (2011) Optimalkan potensi anak dengan game. Jakarta: PT Alexmedia Komputindo.

Wong \& Donna, L, (2008) Buku Ajar Keperawatan Pediatrik. Jakarta: EGC 